\title{
Clinical Manifestation and Management of ADPKD in Western Countries
}

\author{
Claudia Sommerer Martin Zeier \\ Division of Nephrology, Medical University Hospital Heidelberg, Heidelberg, Germany
}

\section{Key Words}

Autosomal dominant polycystic kidney disease $\cdot$ Clinical manifestation · Management · Therapy · Western countries

\begin{abstract}
Background: Autosomal dominant polycystic kidney disease (ADPKD) is the most common hereditary kidney disease in Western countries. The prevalence is between $2.4 / 10,000$ and 3.9/10,000. ADPKD represents a systemic disease resulting in deterioration in renal function. Until now, mutations in two genes (PKD1 and PKD2) have been identified. Recently, the European Medicines Agency (EMA) approved the use of the vasopressin $\mathrm{V} 2$ receptor antagonist tolvaptan to slow the progression of cyst development and renal insufficiency connected with ADPKD in adult patients with chronic kidney disease stages 1-3 at initiation of treatment with evidence of rapidly progressing disease. Whereas the EMA approved the release of tolvaptan, the US Food and Drug Administration (FDA) requested further data on side effects and the selection of patient cohorts who may benefit from treatment. Summary: This review focused on advances in the management and treatment of ADPKD in Western countries. Key Message: ADPKD represents the fourth most common cause of end-stage renal disease (ESRD) in Western countries. ADPKD is a multisystemic disease characterized by the progressive development of bilateral renal cysts, resulting in enlargement of the kidney volume due to cystic formations,
\end{abstract}

hypertension, hematuria, and loss of renal function. ADPKD is associated with high inter- and intrafamilial variability in disease appearance and progression. Patients with PKD1 mutations typically have a more severe phenotype than those with PKD2 mutations. ADPKD is under intensive investigation. Vasopressin and the associated cyclic adenosine monophosphate-related signaling pathways have been demonstrated to be important contributors to cyst growth in ADPKD. Supportive treatments are recommended with the aim of reducing morbidity and mortality associated with disease manifestations. In the past years, several agents have been investigated in ADPKD patients, including mTOR inhibitors, somatostatin analogs, statins, and vasopressin V2 receptor antagonists. Facts from East and West: (1) ADPKD is diagnosed globally by ultrasound detection of kidney enlargement and presence of cysts. Recent analyses of variants of the PKD1 and PKD2 genes by next-generation sequencing in Chinese and Western ADPKD patients might lead to the development of reliable genetic tests. (2) Besides lifestyle changes (low-salt diet, sufficient fluid intake, and no smoking), blood pressure control is the primary nonspecific treatment recommended by Kidney Disease - Improving Global Outcomes (KDIGO) for ADPKD patients. How low the blood pressure target should be and what the means of achieving it are remain open questions depending on the severity of

For the clinical manifestation and management of ADPKD in China, see Xue et al., Kidney Dis 2016;2:111-119.

\section{KARGER}

E-Mail karger@karger.com

www.karger.com/kdd
(C) 2016 S. Karger AG, Basel

2296-9381/16/0023-0120\$39.50/0
Claudia Sommerer, MD

Division of Nephrology, Medical University Hospital Heidelberg Im Neuenheimer Feld 162 DE-69120 Heidelberg (Germany)

E-Mail claudia.sommerer@med.uni-heidelberg.de 
chronic kidney disease and the age of the patients. In a recent Chinese study, diagnostic needle aspiration and laparoscopic unroofing surgery successfully improved infection, pain, and hypertension. Peritoneal dialysis was found to be a feasible treatment for most Chinese ADPKD patients with ESRD. In most Western centers, patients without contraindication are selected for peritoneal dialysis. Kidney transplantation with concurrent bilateral nephrectomy was successful in relieving hypertension and infection in Chinese ADPKD patients. In Western countries, sequential surgical intervention with kidney transplantation after nephrectomy, or the other way round, is preferred in order to reduce risks. (3) The vasopressin 2 receptor antagonist tolvaptan was approved in Europe, Canada, Japan, and Korea to slow down progression of kidney disease in ADPKD patients. Tolvaptan is not yet approved in the USA or in China. mTOR pathway-targeting drugs are currently under evaluation: MTOR inhibitors could slow down the increase in total kidney volume in a cohort of Western and Japanese ADPKD patients. Western studies as well as an ongoing study in China failed to show benefit from rapamycin. A study performed in Italy indicates protective effects of the somatostatin analog octreotide in ADPKD patients. Western and Chinese studies revealed a potential beneficial effect of triptolide, the active substance of the traditional Chinese medicine Tripterygium wilfordii (Lei Gong Teng) to prevent worsening in ADPKD patients.

(c) 2016 S. Karger AG, Base

\section{Introduction}

Autosomal dominant polycystic kidney disease (ADPKD) is the most common hereditary kidney disease [1-3]. It represents the fourth most common cause of end-stage renal disease (ESRD) in Western countries, accounting for $\sim 10 \%$ of European patients on dialysis [4]. In most of the patients, ADPKD is associated with a progressive increase in kidney volume and decline in glomerular filtration rate (GFR) [5]. More than $50 \%$ of patients with ADPKD require renal replacement therapy by the age of 60 years [4]. ADPKD is characterized by the progressive development of bilateral renal cysts, resulting in urine concentration defects, enlargement of the kidney volume due to cystic formations, hypertension, hematuria, acute and chronic pain, cyst and urinary tract infections, and loss of renal function $[6,7]$. It is a slowly progressing disease, with compensatory hyperfiltration of the unaffected tubuli maintaining the GFR within a normal range for a long time [8]. In addition, ADPKD is a multisystemic disease with several extrarenal manifesta- tions including hepatic cysts (in $>90 \%$ of patients aged $>35$ years), pancreatic cysts, intracranial aneurysms, colon diverticulosis, and heart valve defects.

ADPKD is associated with high inter- and intrafamilial variability in disease appearance and progression. Its clinical presentation ranges from asymptomatic to severe impairment due to enlargement of the kidneys and the liver. Disease progression is only partially indicated by specific gene mutations.

The management and treatment strategies for ADPKD have not progressed for a long time. Until now, supportive therapy has been the only available treatment. Recently, new therapeutic options were identified, with specific drugs based on the mechanisms of kidney progression [9].

\section{Prevalence}

ADPKD is one of the leading causes of ESRD, but estimates of its prevalence vary more than 10 -fold. Approximately 1 in every 400-1,000 live births suffers from ADPKD in Western countries $[10,11]$. It is estimated that only half of these cases will be diagnosed during a patient's lifetime as the disease might be clinically inapparent [1].

Population-based studies in a European population determined prevalence rates between 2.41 and 3.89/10,000 $[12,13]$. The European Renal Association and European Dialysis and Transplantation Association (ERA-EDTA) registry data provided prevalence data of 3.29/10,000 [14]. Therefore, ADPKD belongs to the category of rare diseases in Europe (prevalence threshold $<5 / 10,000$ ).

\section{Genetics and Pathophysiology}

ADPKD is a hereditary kidney disease of autosomal dominant inheritance. ADPKD is caused by mutations in the polycystic kidney disease 1 (PKD1) or 2 (PKD2) gene with the gene products polycystin-1 and -2 , nonselective calcium-permeable channels of TRPP2 (transient receptor potential PKD-like 2) [15]. The spontaneous mutation rate is high at up to $8 \%$. Approximately $85 \%$ of families with ADPKD have an abnormality on chromosome 16 (PKD1 locus) [6]. In 15\% of the patients, APDKD is caused by a defect that involves a gene on chromosome 4 (the PKD2 locus).

Patients with PKD1 mutations typically have a more severe phenotype than those with PKD2 mutations [16]. 
Cysts occur earlier in PKD1 disease, as does ESRD (mean age: 54.3 years in PKD1 vs. 74.0 years in PKD2 disease) $[3,17]$. Consequently, false-negative results occur more often when screening young subjects with PKD2 disease.

Ciliary disorders are identified as a cause of cystic kidney diseases [18]. The impact of cilia on renal cyst growth is not completely elucidated, but cilia seem to be responsible for well-ordered cell division and cell migration along the axis of the nephron $[19,20]$. Vasopressin and the associated cyclic adenosine monophosphate (cAMP)related signaling pathways have been demonstrated to be important contributors to cyst growth in ADPKD. The mTORC1 (mammalian target of rapamycin complex 1) signal cascade seems to be more active in ADPKD, and cAMP production is increased [21]. cAMP is associated with enhanced ion and fluid secretion in the lumen of the cyst followed by cyst growth [22]. The vasopressin 2 receptor blocker inhibits the antidiuretic hormone-dependent production of cAMP. This pathophysiological background was the basis for clinical studies on the mTOR inhibitors sirolimus and everolimus, as well as on the vasopressin V2 receptor antagonist tolvaptan, as specific treatment.

\section{Diagnosis and Management}

Diagnosis of ADPKD is the result of radiological imaging [3]. The US Consortium for Radiologic Imaging Studies of Polycystic Kidney Disease (CRISP) documented that kidney enlargement is the first manifestation of the disease [5]. Typical findings are multiple middle-sized cysts within both kidneys increasing to a total kidney volume (TKV) of more than 1 liter prior to deterioration of renal function [23]. Ultrasonography is most commonly used as the imaging modality. The accuracy of ultrasound in diagnosing ADPKD is about $96 \%$ in young patients aged between 15 and 29 years; it is not possible to completely rule out the disease with imaging tools.

Important factors related to the diagnosis of ADPKD include any family history of the disease, the number and types of renal cysts, and the age of a patient. Currently, genetic testing is regularly irrelevant to a definitive diagnosis. In clinical practice, genetic testing is restricted to potential living related kidney donors with negative scans and atypical presentations, especially for patients with a negative family history [7, 24]. Genetics may become more important if better correlations between genotypes and phenotypes can be identified, and if there are consequences for treatment. Screening of asymptomatic chil- dren with a positive family history has not been recommended, due to missing specific treatment options [25]. Screening of children has been limited to measurement of blood pressure as the most important risk factor. In the future, there might be a paradigm shift, as high-risk patients can be detected and specific treatment might be started earlier [26]. A flow diagram on the diagnostics and management of ADPKD is provided in figure 1.

ADPKD progression is highly variable even among individuals within one family, making the prediction of progression for one patient a very challenging process. In the absence of reliable biomarkers, disease modeling may play a role in defining the wider clinical assessment of atrisk patients and assist in practical decision-making [27]. As shown by the CRISP study, total renal volume is the best predictor of progression of chronic kidney disease (CKD) [28]. According to the Kidney Disease - Improving Global Outcomes (KDIGO) Conference in 2014, a baseline examination to determine kidney size is recommended, as TKV is associated with risk of progression and renal failure [25]. TKV can be ascertained by standardized MRI protocols in specialized centers using an ellipsoid formula. ADPKD patients aged below 30 years with a TKV above $1,500 \mathrm{ml}$ are likely to be fast progressors and may require renal replacement therapy within the following 20 years even if their current kidney function is normal. In addition, a recent study demonstrated that in patients with estimated GFR (eGFR) above $70 \mathrm{ml} /$ $\mathrm{min} / 1.73 \mathrm{~m}^{2}$, a TKV of more than $650 \mathrm{ml}$ as measured by ultrasound, or a kidney length longer than $16.5 \mathrm{~cm}$, is a predictor of a decrease in renal function with a sensitivity of $70 \%$ and specificity of $71 \%$ [29].

Other prognostic factors include age, gender, renal function, macrohematuria, and onset of arterial hypertension. Clinical data on disease progression are currently collected in a European study on spontaneous disease progression [30]. Individual risk assessment will be essential for patient-centered treatment decision-making in the future.

\section{Treatment}

\section{General Treatment}

Until recently, no interventions were available to slow the rate of disease progression in ADPKD. Supportive treatments were recommended at the February 2014 KDIGO Controversies Conference, with the aim of reducing morbidity and mortality associated with disease manifestations [25]. Normalization of blood pressure, a 
Fig. 1. Flow diagram on the management of

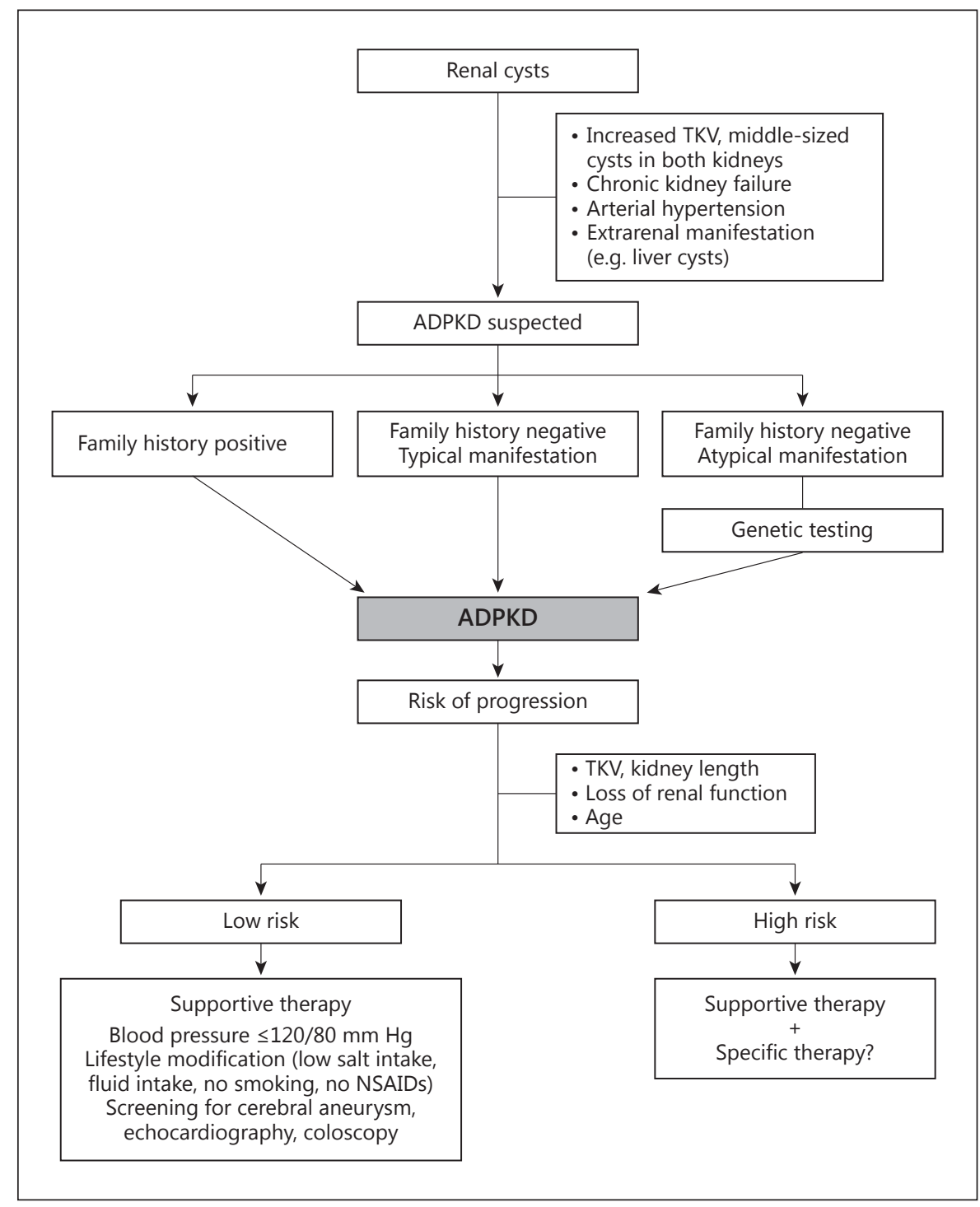
ADPKD [adapted from 49].

salt-reduced diet, sufficient fluid intake (2-3 liters/day), avoidance of smoking and nephrotoxic agents such as nonsteroidal anti-inflammatory drugs, as well as restriction of caffeine were suggested [31]. Of all, the most important supportive treatment was optimization of blood pressure.

Hypertension is a very common complication of ADPKD, occurring in $60-80 \%$ of ADPKD patients early in disease progression. Effective treatment of hypertension is very important to decrease morbidity and mortality of ADPKD patients. Activation of the renin-angiotensin-aldosterone system (RAAS) seems to play a major role in the pathogenesis of hypertension in ADPKD [32]. Based on pathogenic data on hypertension in ADPKD patients, the best treatment of this disease is RAAS inhibitors with angiotensin-converting enzyme inhibitors or angiotensin II receptor blockers.

Generally, a target blood pressure below 140/90 mm $\mathrm{Hg}$ was recommended [33]. However, the HALT-PKD study advised strict blood pressure control $[34,35]$. The HALT-PKD study was a US multicenter trial conducted on more than 1,000 ADPKD patients for 5.5 years. In patients with eGFR above $60 \mathrm{ml} / \mathrm{min} / 1.73 \mathrm{~m}^{2}$, a target blood pressure of 110/70 $\mathrm{mm} \mathrm{Hg}$ was suggested, especially in young patients with a high progression risk. In CKD stage 3 , the target blood pressure should be below $120 / 80 \mathrm{~mm}$ Hg. Double RAAS blockade with a target blood pressure of 120/80 mm Hg or less had no beneficial effects but did 
increase complications among older ADPKD patients [35]. These study results are widely discussed. Especially in patients with CKD stage 4 , such a strict blood pressure control is not advisable, due to possible negative effects on renal function. Blood pressure measurements should be validated by 24 -hour blood pressure profiles at least once a year.

\section{Specific Treatment}

In the past years, several agents have been investigated in ADPKD patients, including mTOR inhibitors, somatostatin analogs, statins, and vasopressin V2 receptor antagonists [9]. Inhibition of mTOR activity has been investigated in multiple clinical studies [36, 37]. The study results showed that TKV growth was slowed by mTOR inhibitors, but renal function did not consequently improve. Another specific treatment approach used somatostatin analogs to inhibit cAMP production by the stimulation of $\mathrm{Ga}_{\mathrm{i}}$. In the ALADIN study, the increase in TKV was lower in patients treated with the somatostatin analog octreotide long-acting release compared to controls within the first year, but a positive effect could not be detected after 3 years of treatment [38]. Octreotide longacting release might be a promising specific treatment for patients with liver cysts; this agent significantly reduced the liver volume, and the reduction was maintained 2 years after treatment had ended [39]. In a small singlecenter study, pravastatin delayed the increase in TKV in young ADPKD patients [40]. However, long-term multicenter studies on statins and ADPKD are missing.

The vasopressin V2 receptor antagonist tolvaptan is the first pharmaceutical agent approved to slow disease progression in ADPKD patients. The vasopressin 2 receptor blocker inhibits the antidiuretic hormone-dependent production of cAMP and reduces cyst growth.

The TEMPO 3:4 trial tested the efficacy of tolvaptan [41]. In this trial, 1,445 patients with ADPKD were randomized to receive either placebo or tolvaptan at $45 \mathrm{mg}$ in the morning and $15 \mathrm{mg}$ in the afternoon, uptitrated to $90 / 30 \mathrm{mg}$ if tolerated. All patients were advised to increase fluid intake. Inclusion criteria were an age of 18-50 years, an estimated creatinine clearance (CockcroftGault) above or equal to $60 \mathrm{ml} / \mathrm{min} / 1.73 \mathrm{~m}^{2}$ and a TKV above or equal to $750 \mathrm{ml}$. An intention-to-treat analysis of this study showed that tolvaptan reduced the rate of TKV growth (primary endpoint) from 5.5 to $2.8 \%$ per year, and the rate of eGFR loss (secondary endpoint) from -3.70 to $-2.72 \mathrm{ml} / \mathrm{min} / 1.73 \mathrm{~m}^{2}$ per year during the 3 -year observation time [41]. When studying the incidence of a $25 \%$ reduction in eGFR, there was a significant $61 \%$ rela- tive risk reduction with tolvaptan (the number needed to treat to prevent one event was $\sim 11$ ). Withdrawal from active treatment occurred in $23 \%$ of cases in the tolvaptan and $14 \%$ of cases in the placebo group. It is assumed that the dialysis-free time might be increased from 4 to 6.5 years if the positive effect of tolvaptan persists over time [42]. However, no study data are available on reducing the incidence of ESRD, due to the short period of observation with a slowly progressive disease [43]. Based on the results of the TEMPO 3:4 trial, the European Medicines Agency (EMA) approved the use of tolvaptan for ADPKD in May 2015 [44]. The regulatory authorities in Japan, Canada, Korea, and Switzerland recently also granted marketing authorization, whereas in the USA the Food and Drug Administration (FDA) requested further efficacy and safety data on this drug [43].

According to the EMA label, tolvaptan 'is indicated to slow the progression of cyst development and renal insufficiency of ADPKD in adults with CKD stages 1 to 3 at initiation of treatment with evidence of rapidly progressing disease'. Two issues need to be clarified: first, the CKD stage and age that qualify patients for treatment, and second, how to define 'evidence of rapidly progressing disease' [45]. The decision to start tolvaptan treatment requires the consideration of many factors besides eligibility, such as contraindications, potential adverse events, as well as patient motivation.

The interesting question is: which patients may benefit from tolvaptan treatment? The ERA-EDTA Working Group on Inherited Kidney Disorders and European Renal Best Practice presented a detailed discussion of this very important aspect [45]. According to the EMA decision, tolvaptan is allowed for patients with CKD stages $1-3$, that is, an eGFR of more than $30 \mathrm{ml} / \mathrm{min} / 1.73 \mathrm{~m}^{2}$. However, the inclusion criterion for the TEMPO 3:4 study was an estimated creatinine clearance (CockcroftGault formula) above or equal to $60 \mathrm{ml} / \mathrm{min} / 1.73 \mathrm{~m}^{2}$ [41]. This difference might be softened by knowing that the creatinine clearance overestimates the GFR, and several patients with an eGFR estimated with the CKD-epi formula were enrolled in the TEMPO study $[41,46]$. However, the number of patients with CKD stage $3 b$ was very small with 42 patients (i.e. only $3 \%$ of the patient cohort). From a scientific and clinical point of view, it might be concluded that there are no reliable results on tolvaptan treatment for patients with CKD stage 3. The ERA-EDTA recommendation states that the information on the benefit-to-risk ratio regarding tolvaptan in patients with CKD stage $3 \mathrm{~b}$ is too limited to advise treatment [45]. 
Table 1. Tolvaptan treatment for ADPKD patients according to the drug label

\section{Indication}

To slow progression of cyst development and renal failure in adult ADPKD patients with CKD stages $1-3$ with fast disease progression

\section{Contraindications}

Elevated liver enzymes or other signs of liver impairment; hypersensitivity; volume depletion; hypernatremia; patients who cannot feel or respond to thirst; pregnancy or breast-feeding; incompliance to monthly liver enzyme control

\section{Special warnings}

Idiosyncratic hepatotoxicity; urine outflow obstruction; access to water or dehydration; fluid and electrolyte disturbances; anaphylaxis, lactose, or galactose intolerance; diabetes mellitus; increased uric acid; interactions with drugs metabolized by CYP3A inhibitors, CYP2A inducers, and CYP3A substrates; digoxin or other drugs which may increase sodium concentration; vasopressin analogs; skin inspections at regular intervals (neoplasia); measurements of the intraocular pressure at regular intervals (glaucoma)

$\mathrm{ADPKD}=$ Autosomal dominant polycystic kidney disease.

Table 3. Description of the Mayo classification of ADPKD [50]

\begin{tabular}{llllll}
\hline Mayo classification & $1 \mathrm{~A}$ & $1 \mathrm{~B}$ & $1 \mathrm{C}$ & $1 \mathrm{D}$ & $1 \mathrm{E}$ \\
\hline $\begin{array}{l}\text { TKV increase per year, \% } \\
\text { eGFR slope per year, } \\
\begin{array}{c}\mathrm{m} / \mathrm{min} / 1.73 \mathrm{~m}^{2} \\
\text { Incidence of ESRD at } \\
10 \text { years, \% }\end{array}\end{array}$ & -0.1 & -1.2 & -2.5 & -3.4 & -4.6 \\
\hline
\end{tabular}

ADPKD = Autosomal dominant polycystic kidney disease; eGFR = estimated glomerular filtration rate; ESRD = end-stage renal disease; $\mathrm{TKV}=$ total kidney volume.

ADPKD patients with CKD stage 1 were excluded from tolvaptan treatment by the UK National Institute for Health and Care Excellence (NICE) recommendations [47]. This decision was based on a cost-effectiveness analysis that was performed on the TEMPO 3:4 study data. The effect of tolvaptan in decreasing the rate of change in eGFR was 16,29 , and $31 \%$ at CKD stage 1,2 , and 3 , respectively [48].

However, the eGFR remains stable for a long time; therefore, it is difficult to assess disease progression by changes in GFR at this early CKD stage. The decrease in TKV growth with tolvaptan versus placebo was 40,60 , and
Table 2. Recommendations of the ERA-EDTA Working Group on Tolvaptan Treatment [45]

Recommendation on tolvaptan treatment according to the ERA-EDTA Working Group

1 1.1 Patient age $<50$ years with CKD stages $1-3$ a who are likely to have rapidly progressing disease, but CKD stage must be reinterpreted in conjunction with age

1.2 No start of tolvaptan in patients aged 30-40 years with CKD stage 1

1.3 No start of tolvaptan in patients aged $40-50$ years with CKD stage 1 or 2

2 Rapid progression is defined by an annual eGFR decline $\geq 5 \mathrm{ml} /$ $\mathrm{min} / 1.73 \mathrm{~m}^{2}$ in 1 year, and/or $\geq 2.5 \mathrm{ml} / \mathrm{min} / 1.73 \mathrm{~m}^{2}$ per year over a period of 5 years

3 A TKV increase of $>5 \%$ per year defines rapid progression

44.1 The use of the Mayo classification of ADPKD ('typical' or 'atypical' morphology) to define five classes of patients according to prognosis is recommended

4.2 In patients with Mayo class $1 \mathrm{C}-1 \mathrm{E}$ disease, rapid disease progression is likely

4.3 In patients with atypical morphology of ADPKD, rapid disease progression is unlikely

4.4 In patients aged $>45$ years and a kidney length of $>16.5 \mathrm{~cm}$ (ultrasound), rapid progressive disease is likely

$5 \quad$ Rapid disease progression is likely in patients with truncating PKD1 mutation in conjunction with early onset of clinical symptoms

6 In patients with a family history of ESRD $<58$ years, reassessments for rapid progression should be performed on a 3- to 5-yearly basis

$7 \quad$ A hierarchical decision algorithm is suggested to assess whether ADPKD patients are rapid progressors and may qualify for specific treatment

$8 \quad 8.1$ Adverse effects and impacts on lifestyle should be discussed when considering tolvaptan treatment

8.2 Contraindications and adverse effects should be taken into account when considering tolvaptan treatment

8.3 Prescription and documentation of safety monitoring of tolvaptan should be performed under supervision of ADPKD experts

99.1 The tolvaptan starting dose should be $45 \mathrm{mg}$ in the morning and $15 \mathrm{mg}$ in the evening

9.2 If tolerated, uptitration to $60 / 30$ and $90 / 30 \mathrm{mg}$ is suggested

9.3 Tolvaptan treatment should be stopped if renal function declines to end-stage renal failure

$\mathrm{ADPKD}=$ Autosomal dominant polycystic kidney disease; $\mathrm{CKD}=$ chronic kidney disease; eGFR = estimated GFR; ESRD = end-stage renal disease; TKV = total kidney volume.

$40 \%$ at CKD stage 1,2 , and 3, respectively [48], and even this patient cohort might benefit from tolvaptan treatment. Nonetheless, it has also to be kept in mind that in this patient cohort, treatment will last many years and there are no safety and efficacy data on patients on tolvaptan treatment for more than 10 years. According to the ERA- 
EDTA, in this patient cohort tolvaptan should be limited to ADPKD patients with rapidly progressive disease [45].

According to the EMA, all ADPKD patients older than 18 years are eligible for treatment. However, the TEMPO 3:4 study inclusion criteria require a patient age between 18 and 50 years [41]. Therefore, data on safety and efficacy are missing for patients older than 50 years. In addition, the ERA-EDTA did not recommend treating patients aged 40-50 years with an eGFR above $60 \mathrm{ml} /$ $\mathrm{min} / 1.73 \mathrm{~m}^{2}$ (CKD stages 1 and 2 ) as well as patients aged $30-40$ years with an eGFR above $90 \mathrm{ml} / \mathrm{min} / 1.73 \mathrm{~m}^{2}$ (CKD stage 1), since these patients show slowly progressive disease [45].

Major side effects of tolvaptan comprise polyuria and nocturia caused by inhibition of the effect of antidiuretic hormone as well as liver toxicity (table 1). The risk of dehydration and increase in liver enzymes in particular has to be taken into account, and regular follow-up visits including detailed documentation are necessary. Detailed knowledge of ADPKD diseases and its management has to be demonstrated prior to obtaining the approval for tolvaptan prescription (in Germany). Tolvaptan therapy costs are high and might be comparable to the annual costs of hemodialysis treatment in Europe [4, 49].

The general recommendations by the ERA-EDTA Working Group concerning tolvaptan treatment in ADPKD are given in table 2. These recommendations are based on the Mayo classification for prediction of disease progression in ADPKD by TKV and age [50]. A brief description of the Mayo class 1 data is provided in table 3.
Due to the multiple side effects of this drug, it is necessary to clearly identify those patients who may benefit from treatment. However, the decision on starting tolvaptan treatment is always an individual one, taking into account a patient's risk profile and motivation.

\section{Conclusions}

ADPKD is one of the leading causes of ESRD. It is a systemic disease. Its diagnosis is made by ultrasound; genetic testing is developing and might be important in the future. The most important supportive treatment is regulation of blood pressure. Recently, a specific treatment option was introduced with tolvaptan, a vasopressin 2 receptor antagonist. Whereas the EMA approved the release of tolvaptan, the FDA requested further information on side effects and the selection of patient cohorts who may benefit from treatment. Another international multicenter study is currently conducted to investigate its efficacy and safety in ADPKD patients with chronic kidney failure (eGFR 25-65 ml/min/1.73 $\mathrm{m}^{2}$ ). Patients to be treated with tolvaptan have to be selected carefully, and tolvaptan should be restricted to those with rapid disease progression.

\section{Conflict of Interest Statement}

All authors declare that they have no competing interests.

\section{References}

1 Steinman TI: Polycystic kidney disease: a 2011 update. Curr Opin Nephrol Hypertens 2012;21:189-194.

-2 Devuyst O, Knoers NV, Remuzzi G, Schaefer F; Board of the Working Group for Inherited Kidney Diseases of the European Renal Association and European Dialysis and Transplant Association: Rare inherited kidney diseases: challenges, opportunities, and perspectives. Lancet 2014;383:1844-1859.

- 3 Torres VE, Harris PC, Pirson Y: Autosomal dominant polycystic kidney disease. Lancet 2007;369:1287-1301.

-4 Spithoven EM, Kramer A, Meijer E, et al: Analysis of data from the ERA-EDTA Registry indicates that conventional treatments for chronic kidney disease do not reduce the need for renal replacement therapy in autosomal dominant polycystic kidney disease. Kidney Int 2014;86:1244-1252.
5 Grantham JJ, Torres VE, Chapman AB, Guay-Woodford LM, Bae KT, King BF Jr, et al; CRISP Investigators: Volume progression in polycystic kidney disease. $\mathrm{N}$ Engl J Med 2006;354:2122-2130.

6 Grantham JJ: Clinical practice. Autosomal dominant polycystic kidney disease. $\mathrm{N}$ Engl J Med 2008;359:1477-1485.

7 Ong AC, Devuyst O, Knebelmann B, Walz G: Autosomal dominant polycystic kidney disease: the changing face of clinical management. Lancet 2015;385:1993-2002.

8 Higashihara E, Horie S, Muto S, Mochizuki T, Nishio S, Nutahara K: Renal disease progression in autosomal dominant polycystic kidney disease. Clin Exp Nephrol 2012;16:622628.

-9 Wüthrich RP, Mei C: Pharmacological management of polycystic kidney disease. Expert Opin Pharmacother 2014;15:1085-1095.
10 Gabow PA: Autosomal dominant polycystic kidney disease. N Engl J Med 1993;329:332342.

11 Levy M, Feingold J: Estimating prevalence in single-gene kidney diseases progressing to renal failure. Kidney Int 2000;58:925-943.

-12 Neumann HP, Jilg C, Bacher J, Nabulsi Z, Malinoc A, Hummel B, et al; Else-KroenerFresenius-ADPKD-Registry: Epidemiology of autosomal-dominant polycystic kidney disease: an in-depth clinical study for southwestern Germany. Nephrol Dial Transplant 2013;28:1472-1487.

13 Patch C, Charlton J, Roderick PJ, Gulliford MC: Use of antihypertensive medications and mortality of patients with autosomal dominant polycystic kidney disease: a population-based study. Am J Kidney Dis 2011;57:856-862. 
14 ERA-EDTA Registry: ERA-EDTA Registry Annual Report 2014. Amsterdam, Academic Medical Center, Department of Medical Informatics, 2016. http://www.era-edta-reg.org/ files/annualreports/pdf/AnnRep2014.pdf (accessed 19 August 2016).

$\checkmark 15$ Ong AC, Harris PC: Molecular pathogenesis of ADPKD: the polycystin complex gets complex. Kidney Int 2005;67:1234-1247.

16 Cornec-Le Gall E, Audrézet MP, Chen JM, Hourmant M, Morin MP, Perrichot R, et al: Type of PKD1 mutation influences renal outcome in ADPKD. J Am Soc Nephrol 2013;24: 1006-1013.

- 17 Hateboer N, van Dijk MA, Bogdanova N, Coto E, Saggar-Malik AK, San Millan JL, et al: Comparison of phenotypes of polycystic kidney disease types 1 and 2. European PKD1PKD2 Study Group. Lancet 1999;353:103107.

18 Hildebrandt F, Benzing T, Katsanis N: Ciliopathies. N Engl J Med 2011;364:1533-1543.

19 Fischer E, Legue E, Doyen A, Nato F, Nicolas JF, Torres V, et al: Defective planar cell polarity in polycystic kidney disease. Nat Genet 2006;38:21-23

20 Lienkamp SS, Liu K, Karner CM, Carroll TJ, Ronneberger $\mathrm{O}$, Wallingford JB, et al: Vertebrate kidney tubules elongate using a planar cell polarity-dependent, rosette-based mechanism of convergent extension. Nat Genet 2012;44:1382-1387.

21 Harris PC, Torres VE: Genetic mechanisms and signaling pathways in autosomal dominant polycystic kidney disease. J Clin Invest 2014;124:2315-2324.

-22 Mangoo-Karim R, Uchic M, Lechene C, Grantham JJ: Renal epithelial cyst formation and enlargement in vitro: dependence on cAMP. Proc Natl Acad Sci USA 1989;86: 6007-6011.

-23 Chapman AB, Bost JE, Torres VE, GuayWoodford L, Bae KT, Landsittel D, et al: Kidney volume and functional outcomes in autosomal dominant polycystic kidney disease. Clin J Am Soc Nephrol 2012;7:479-486.

24 Simms RJ, Travis DL, Durkie M, Wilson G, Dalton A, Ong AC: Genetic testing in the assessment of living related kidney donors at risk of autosomal dominant polycystic kidney disease. Transplantation 2015;99:1023-1029.

-25 Chapman AB, Devuyst O, Eckardt KU, Gansevoort RT, Harris T, Horie S, et al; Conference Participants: Autosomal-dominant polycystic kidney disease (ADPKD): executive summary from a Kidney Disease: Improving Global Outcomes (KDIGO) Controversies Conference. Kidney Int 2015;88:17-27.

26 Helal I, Reed B, McFann K, Yan XD, FickBrosnahan GM, Cadnapaphornchai M, et al: Glomerular hyperfiltration and renal progression in children with autosomal dominant polycystic kidney disease. Clin J Am Soc Nephrol 2011;6:2439-2443.

-27 Schrier RW, Brosnahan G, Cadnapaphornchai MA, Chonchol M, Friend K, Gitomer B, et al: Predictors of autosomal dominant poly- cystic kidney disease progression. J Am Soc Nephrol 2014;25:2399-2418.

28 King BF, Torres VE, Brummer ME, Chapman $\mathrm{AB}$, Bae KT, Glockner JF, et al; Consortium for Radiologic Imaging Studies of Polycystic Kidney Disease (CRISP): Magnetic resonance measurements of renal blood flow as a marker of disease severity in autosomal-dominant polycystic kidney disease. Kidney Int 2003;64: 2214-2221.

29 Bhutani H, Smith V, Rahbari-Oskoui F, Mittal A, Grantham JJ, Torres VE, et al; CRISP Investigators: A comparison of ultrasound and magnetic resonance imaging shows that kidney length predicts chronic kidney disease in autosomal dominant polycystic kidney disease. Kidney Int 2015;88:146-151.

30 Petzold K, Gansevoort RT, Ong AC, Devuyst O, Rotar L, Eckardt KU, et al: Building a network of ADPKD reference centres across Europe: the EuroCYST initiative. Nephrol Dial Transplant 2014;29(suppl 4):iv26-iv32.

31 Torres VE, Grantham JJ, Chapman AB, Mrug $\mathrm{M}$, Bae KT, King BF Jr, et al; Consortium for Radiologic Imaging Studies of Polycystic Kidney Disease (CRISP): Potentially modifiable factors affecting the progression of autosomal dominant polycystic kidney disease. Clin J Am Soc Nephrol 2011;6:640-647.

32 Tkachenko O, Helal I, Shchekochikhin D, Schrier RW: Renin-angiotensin-aldosterone system in autosomal dominant polycystic kidney disease. Curr Hypertens Rev 2013;9:12-20

33 Wheeler DC, Becker GJ: Summary of KDIGO guideline. What do we really know about management of blood pressure in patients with chronic kidney disease? Kidney Int 2013; 83:377-383

34 Schrier RW, Abebe KZ, Perrone RD, Torres VE, Braun WE, Steinman TI, et al; HALTPKD Trial Investigators: Blood pressure in early autosomal dominant polycystic kidney disease. N Engl J Med 2014;371:2255-2266.

35 Torres VE, Abebe KZ, Chapman AB, Schrier RW, Braun WE, Steinman TI, et al; HALTPKD Trial Investigators: Angiotensin blockade in late autosomal dominant polycystic kidney disease. N Engl J Med 2014;371:2267-2276.

- 36 Serra AL, Poster D, Kistler AD, Krauer F, Raina S, Young J, et al: Sirolimus and kidney growth in autosomal dominant polycystic kidney disease. N Engl J Med 2010;363:820 829.

37 Walz G, Budde K, Mannaa M, Nürnberger J, Wanner C, Sommerer C, et al: Everolimus in patients with autosomal dominant polycystic kidney disease. N Engl J Med 2010;363:830840.

8 Caroli A, Perico N, Perna A, Antiga L, Brambilla P, Pisani A, et al; ALADIN Study Group: Effect of longacting somatostatin analogue on kidney and cyst growth in autosomal dominant polycystic kidney disease (ALADIN): a randomised, placebo-controlled, multicentre trial. Lancet 2013;382:1485-1495.

- 39 Pisani A, Sabbatini M, Imbriaco M, Riccio E, Rubis N, Prinster A, et al; ALADIN Study
Group: Long-term effects of octreotide on liver volume in patients with polycystic kidney and liver disease. Clin Gastroenterol Hepatol 2016;14:1022-1030.

40 Cadnapaphornchai MA, George DM, McFann K, Wang W, Gitomer B, Strain JD, et al: Effect of pravastatin on total kidney volume, left ventricular mass index, and microalbuminuria in pediatric autosomal dominant polycystic kidney disease. Clin J Am Soc Nephrol 2014;9:889-896.

41 Torres VE, Chapman AB, Devuyst O, Gansevoort RT, Grantham JJ, Higashihara E, et al: Tolvaptan in patients with autosomal dominant polycystic kidney disease. N Engl J Med 2012;367:2407-2418.

42 Erickson KF, Chertow GM, Goldhaber-Fiebert JD: Cost-effectiveness of tolvaptan in autosomal dominant polycystic kidney disease. Ann Intern Med 2013;159:382-389.

43 Reference to FDA Complete Response Letter 2013. http://www.businesswire.com/news/ home/20130829006215/en/Otsuka-ReceivesComplete-Response-Letter-U.S.-Food (accessed 20 August 2016).

44 European Medicines Agency: Public Assessment Report Jinarc. http://www.ema.europa. eu/docs/en_GB/document_library/EPAR_ Public_assessment_report/human/002788/ WC500187923.pdf (accessed 20 August 2016)

45 Gansevoort RT, Arici M, Benzing T, Birn H, Capasso G, Covic A, et al: Recommendations for the use of tolvaptan in autosomal dominant polycystic kidney disease: a position statement on behalf of the ERA-EDTA Working Groups on Inherited Kidney Disorders and European Renal Best Practice. Nephrol Dial Transplant 2016;31:337-348.

46 Shemesh O, Golbetz H, Kriss JP, Myers BD: Limitations of creatinine as a filtration marker in glomerulopathic patients. Kidney Int $1985 ; 28: 830-838$

47 National Institute for Health and Care Excellence: Final Appraisal Determination: Tolvaptan for Treating Autosomal Dominant Polycystic Kidney Disease. http://www.nice. org.uk/guidance/TA358/documents/kidneydisease-autosomal-dominant-polycystictolvaptanid652-final-appraisaldetermination-document 2 (accessed 20 August 2016).

48 Torres VE, Higashihara E, Devuyst O, Chapman $\mathrm{AB}$, Gansevoort RT, Grantham JJ, et al; TEMPO 3:4 Trial Investigators: Effect of tolvaptan in autosomal dominant polycystic kidney disease by CKD stage: results from the TEMPO 3:4 trial. Clin J Am Soc Nephrol 2016;11:803-811

49 Kühn WE, Walz G: The treatment of autosomal dominant polycystic kidney disease. Dtsch Arztebl Int 2015;112:884-890.

50 Irazabal MV, Rangel LJ, Bergstralh EJ, Osborn SL, Harmon AJ, Sundsbak JL, et al; CRISP Investigators: Imaging classification of autosomal dominant polycystic kidney disease: a simple model for selecting patients for clinical trials. J Am Soc Nephrol 2015;26:160-172. 